\title{
Fabrication of Large Area Broadband and Omnidirectional Antireflective Transparent Foils by Roll-to-Roll Extrusion Coating
}

Murthy, Swathi; Lotz, Mikkel Rønne; Feidenhans'l, Nikolaj Agentoft; Madsen, Morten H.; Pedersen, Henrik Chresten; Pranov, Henrik; Taboryski, Rafael J.

\section{Published in:}

Macromolecular Materials \& Engineering

Link to article, DOI:

10.1002/mame.201700027

Publication date:

2017

Document Version

Peer reviewed version

Link back to DTU Orbit

Citation (APA):

Murthy, S., Lotz, M. R., Feidenhans'l, N. A., Madsen, M. H., Pedersen, H. C., Pranov, H., \& Taboryski, R. J. (2017). Fabrication of Large Area Broadband and Omnidirectional Antireflective Transparent Foils by Roll-to-Roll Extrusion Coating. Macromolecular Materials \& Engineering, [1700027]. https://doi.org/10.1002/mame.201700027

\section{General rights}

Copyright and moral rights for the publications made accessible in the public portal are retained by the authors and/or other copyright owners and it is a condition of accessing publications that users recognise and abide by the legal requirements associated with these rights.

- Users may download and print one copy of any publication from the public portal for the purpose of private study or research.

- You may not further distribute the material or use it for any profit-making activity or commercial gain

- You may freely distribute the URL identifying the publication in the public portal 


\title{
Fabrication of large area broad band and omnidirectional anti-reflective transparent foils by roll-to-roll extrusion coating
}

Swathi Murthy ${ }^{1}$, Mikkel Rønne Lotz ${ }^{2}$, Nikolaj Feidenhans’’ ${ }^{3}$, Morten H. Madsen ${ }^{3}$, Henrik C.

Pedersen $^{1}$, Henrik Pranov ${ }^{4}$, and Rafael Taboryski ${ }^{2, *}$

${ }^{1}$ Department of Photonics Engineering, Technical University of Denmark, Frederiksborgvej 399, DK-4000 Roskilde, Denmark

${ }^{2}$ DTU Nanotech, Technical University of Denmark, Kgs. Lyngby, Denmark

${ }^{3}$ Danish Fundamental Metrology A/S, Matematiktorvet 307, Kgs. Lyngby, Denmark

${ }^{4}$ Heliac ApS, Ambolten 8, 2970 Hørsholm, Denmark

* Corresponding author, rata@nanotech.dtu.dk

\begin{abstract}
This study investigates the fabrication and performance of broadband and omnidirectional antireflective polymer foils, in the visible spectrum (400 nm - $800 \mathrm{~nm}$ ), consisting of sub wavelength inverted moth eye structures. The foils are fabricated by a, high throughput roll-to-roll extrusion coating process allowing structuring on both sides at a rate of $60 \mathrm{~m} / \mathrm{min}$, with web width $45 \mathrm{~cm}$. The highest average transmittance obtained in the visible spectrum is (98 \pm 1 ) \%; compared with (92 \pm 1) \% for the unstructured foil. The anti-reflective foil shows no significant difference in transmittance between normal incidence and incidence up to at least $60^{\circ}$. The foil performance is also investigated for different depths $(D p)$ and shapes of structures. The transmittance initially increases with $D p$ and reaches a maximum at $D p \sim 120 \mathrm{~nm}$. For process parameters yielding greater depths, other shape factors also play a critical role in the foil's anti-reflective properties.
\end{abstract}




\section{Key words}

Metamaterials, optical nanostructures, sub-wavelength materials, materials science, anti-reflective surfaces, nano-fabrication, moth-eye nano-structures, roll-to-roll fabrication, polymer rheology

\section{ToC graphic}

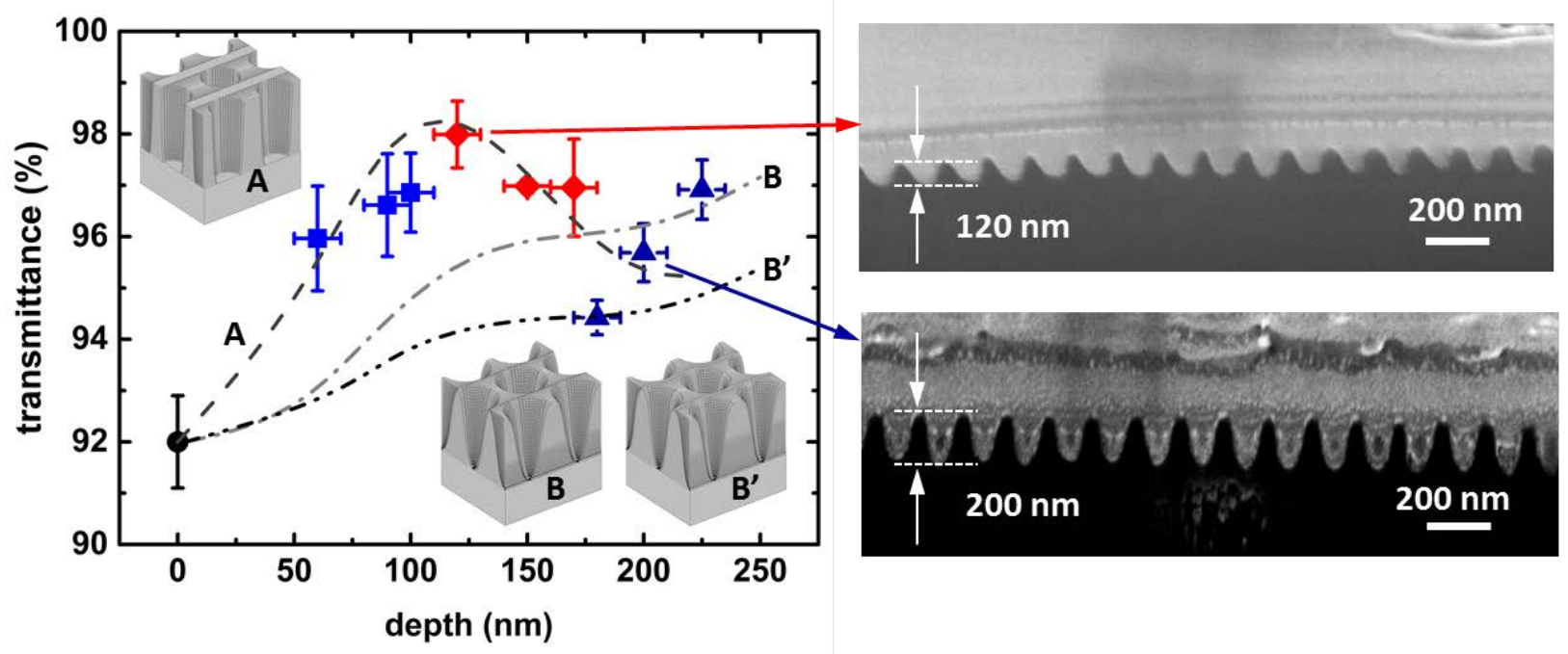




\section{Introduction}

The use of subwavelength surface reliefs for counteracting Fresnel reflections is well known, ${ }^{[1]}$ and has advantages in terms of broader spectral range and wider acceptance angles when compared to quarter wavelength anti-reflective coatings with index matching dielectrics that are presently used in consumer products like lenses, tablets etc. ${ }^{[2,3]}$ The anti-reflective (AR) reliefs are also known as "moth-eye" structures ${ }^{[4,5]}$ after the discovery of such structures in the cornea of nocturnal moths, for disguise against predators, ${ }^{[6]}$ but are also encountered in other insects ${ }^{[7]}$. The classical moth-eye AR structure consists of hexagonally arranged tapered nano-pillars. ${ }^{[8]}$ The AR effect has also been reported for random structures, most notably for the "black Si” or "nano-grass” structures, which are fabricated by a maskless reactive ion-etching (RIE) process; however these structures exhibit light scattering in the visible spectrum, rendering polymer surfaces replicated from black silicon less transparent. ${ }^{[9]}$ The moth-eye effect is well understood in terms of the so-called effective medium theory which employs a graded index matching principle ${ }^{[10]}$ for a tapered subwavelength two-dimensional surface structure. ${ }^{[11]}$

Implementing subwavelength moth-eye type AR functionalities in consumer products is however a considerable challenge today, as it requires direct processing with advanced nano-fabrication methods, such as e-beam lithography, ${ }^{[12]}$ interference lithography, ${ }^{[13]}$ nanoimprint lithography, ${ }^{[14]}$ replication from anodized aluminum oxide, ${ }^{[3]}$ and colloidal lithography, ${ }^{[8,15]}$ to produce surface features of size below $200 \mathrm{~nm}$. In a set of previous publications, we demonstrated roll-to-roll extrusion coating (R2R-EC) for replication of nanopillar ${ }^{[16]}$ and nano-pit ${ }^{[17]}$ structures in PP with diameter below $100 \mathrm{~nm}$, and for replication of nano-grass structures with super-hydrophobic properties $^{[18]}$. Here we demonstrate the application of R2R-EC for the replication of subwavelength tapered nano-pit structures with pronounced AR properties. R2R fabrication of AR moth-eye 
structures were also demonstrated by Burghoorn et al., ${ }^{[19]}$ who developed a R2R UV NIL pilot scale process and produced moth eye-structured Ormocomp coatings on PET at line speeds up to two meters per minute. The R2R-EC process is however much faster allowing, 10-60 m/min line speeds, and while in Burghoorn et al. formed the structures in Ormocomp, a rather expensive material, our structures are formed in PP, which is a very cheap common polymer. Further, here we report on a novel inverted moth-eye structure comprising tapered nano-pits. Finally, we show how the rheology of the process must be taken into account in order to understand the obtained replication of the AR structures.

\section{Experimental Section}

In this article, we report on the roll-to-roll fabrication of broadband and omnidirectional, subwavelength AR structures, for the visible wavelength region, based on the moth-eye effect ${ }^{[4]}$. The structures were originated by e-beam lithography on Si and then replicated in polymer by a novel, high throughput roll-to-roll-extrusion coating (R2R-EC) process $^{[16,20]}$

\subsection{Si master fabrication}

Hexagonal array of nano-pits of period $\sim 175 \mathrm{~nm}$ and diameter of $\sim 100 \mathrm{~nm}$ were exposed in a positive resist (ZEP-520A, ZEON Chemicals) by e-beam lithography. To achieve high writing speed, potentially up to $1 \mathrm{~cm}^{2} / \mathrm{s}$, single spot exposure method was used. ${ }^{[21]}$ The Si master was later etched, using the exposed resist as an etch mask, in an ICP metal etcher, SPTS serial number MP0637. In order to obtain sloped sidewalls $\mathrm{BCl}_{3}$ and $\mathrm{HBr}$ were used as the reactive gasses during etching. The resulting nano-pits in Si have a depth of $\sim 240 \mathrm{~nm}$, diameter $\sim 100 \mathrm{~nm}$ and side wall angle $\sim 79^{\circ}$. 


\subsection{Extrusion coating}

The structured Si master was converted into R2R polymer shims, with the negative surface relief, by Inmold A/S, Denmark. The shims were mounted using double adhesive tape on the cooling roller, whose temperature was varied between $15{ }^{\circ} \mathrm{C}$ and $70{ }^{\circ} \mathrm{C}$ by running cooling water through it. The structures were replicated in PP, (WF420HMS, Borealis) on a PET carrier foil by R2R-EC ${ }^{[16]}$ on the pilot extruder at Danapak A/S (Denmark). It consists of a $25 \mathrm{~mm}$ extruder (BfA Plastic GmbH), 35 mm extruder (AXON Plastics Machinery AB), and an EPOCH nozzle with a respective 3-layer feedblock (Cloeren Inc). During the R2R-EC the PP melt curtain was extruded through a flat nozzle at a constant feed rate of $90 \mathrm{~g} / \mathrm{m}^{2}$ at $10 \mathrm{~m} / \mathrm{min}$, and then laminated onto the carrier PET carrier foil, by squeezing it between the structured cooling roller and the flexible counter roller. The force applied to the nip was maintained at $7 \mathrm{kN} / \mathrm{m}$. Finally, the structured foil was wound-up onto a winding roller. The roller line speed $V_{R}$ was varied between $10 \mathrm{~m} / \mathrm{min}, 30 \mathrm{~m} / \mathrm{min}$ and $60 \mathrm{~m} / \mathrm{min}$. For double side structured foil, the single side structured foil fabricated at $V_{R}=60 \mathrm{~m} / \mathrm{min}$ and $T_{C}=70$

${ }^{0} \mathrm{C}$ was wound up and used a carrier foil for a second EC run to structure the opposite side with the same parameters.

\subsection{Optical characterization}

Transmittance spectra were obtained with a custom build spectrophotometer, featuring a broad band white light source (Ocean optics HPX-2000, high power xenon source), and a calibrated spectrometers (USB2000+VIS-NIR-ES and USB2000 UV-VIS, Ocean Optics Inc., USA) connected to an integrating sphere. The entrance port of the integrating sphere was $1 \mathrm{~cm}$ in diameter. The xenon source provides unpolarized light in the range $400 \mathrm{~nm}$ to $800 \mathrm{~nm}$, effectively defining the wavelength boundaries on the transmittance spectrum due to significant noise when the intensity drops. For each sample the total film transmittance (through both the structured and 
unstructured film interface), $T_{\text {tot }}$, was determined as the mean of three transmittance intensity measurements, $I_{\text {meas }}$, at different positions on the sample all corrected with a reference measurement of the light source, $I_{r e f}$, and a dark measurement with the light turned off, $I_{\text {dark }}$. The illuminating spot size was $\sim 3 \mathrm{~mm}$.

$$
T_{\text {tot }}=\frac{I_{\text {meas }}-I_{\text {dark }}}{I_{\text {ref }}-I_{\text {dark }}}
$$

For single side structured samples, by comparing the total transmittance of the structured and unstructured areas of the film, it is possible to determine the transmittance of the structured interface alone and then calculate the total transmittance corresponding to the transmittance for both the sides of the film structured:

$$
\begin{gathered}
T_{t o t, 0}=T_{0}^{2}, \\
T_{t o t, 1}=T_{0} \times T_{1}, \\
T_{t o t, 2}=T_{1}^{2}=\frac{T_{t o t, 1}^{2}}{T_{t o t, 0}},
\end{gathered}
$$

where $T_{t o t, 0}, T_{t o t, 1}$, and $T_{t o t, 2}$ are the total transmittances through the unstructured film, the single side structured film, and the double side structured film respectively, whereas, $T_{0}$ is the transmittance through one unstructured interface, and $T_{1}$ is the transmittance through one structured interface. Absorption in the bulk film is assumed to be negligible. The \pm on the transmittance values indicate the standard deviation of the mean within the full measuring range.

\subsection{FIB-SEM imaging}

The FIB-SEM images were made using a Helios NanoLAB 600 instrument from FEI. A standard FIB-SEM procedure was used to acquire the images. A platinum layer was deposited on a small area of structured surface, to protect the structures during the milling process with Ga+ ions. The 
FIB cut was made at $30 \mathrm{kV}$ acceleration voltage, and the cross-section was viewed by SEM at $3 \mathrm{kV}$ acceleration voltage.

\subsection{Simulation}

The simulations were carried out using the MATLAB-based electromagnetic simulation program Grating Diffraction Calculator (GD-Calc), which employs the Rigorous Coupled-Wave method (RCW) to compute the diffraction efficiencies of optical grating structures. The structured surface is divided into layers/strata that are uniform in the z-direction. Scattering matrices and Floquet's principle are used to describe the individual boundary conditions at each strata interface and solve the Maxwell's equations accordingly.

The model is comprised of three spatial sections; a transparent superstrate (air), a substrate (PP) and an intermediate section containing the periodic nano-pit structures in PP. The refractive index of air and PP are assumed to be 1 and 1.5 respectively. The transmission curves, in the visible spectrum (400 nm - $800 \mathrm{~nm}$ ) were then calculated for either a truncated cone or a sigmoidal shaped, hexagonal array of nano-pits with period $165 \mathrm{~nm}$ (dimensions obtained from the corresponding SEM images of the structured PP foils), at different depths.

\section{Results and Discussion}

. By exploiting the rheology of the replication process, we varied the depth and shape of nano-pits (inverted moth-eye structures) and demonstrated that the maximum average total transmittance of $(98 \pm 1) \%$ in the visible spectrum $(400 \mathrm{~nm}-800 \mathrm{~nm})$ is surprisingly not obtained for the deepest structures, but for structures with aspect ratio $\sim 1$. For comparison, the unstructured foil has an average transmittance of $(92 \pm 1) \%$ in accordance with the Fresnel reflection formula $R=2\left(\frac{1-n}{1+n}\right)^{2}$ for two air/polymer interfaces and a refractive index $n \approx 1.5$ for the polymer, at normal incidence. A 
foil with AR structures on both sides was fabricated at a rate of $60 \mathrm{~m} / \mathrm{min}$, with a web width of 45 $\mathrm{cm}$, and showed no degradation of its omnidirectional AR performance for acceptance angles up to at least $60^{\circ}$. Performance of the foil for acceptance angles above $60^{\circ}$ could not be measured due to limitation of the measurement set-up.

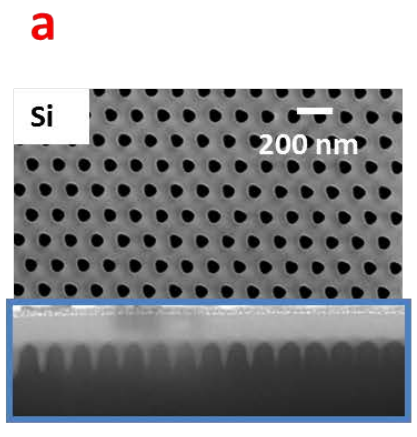

e

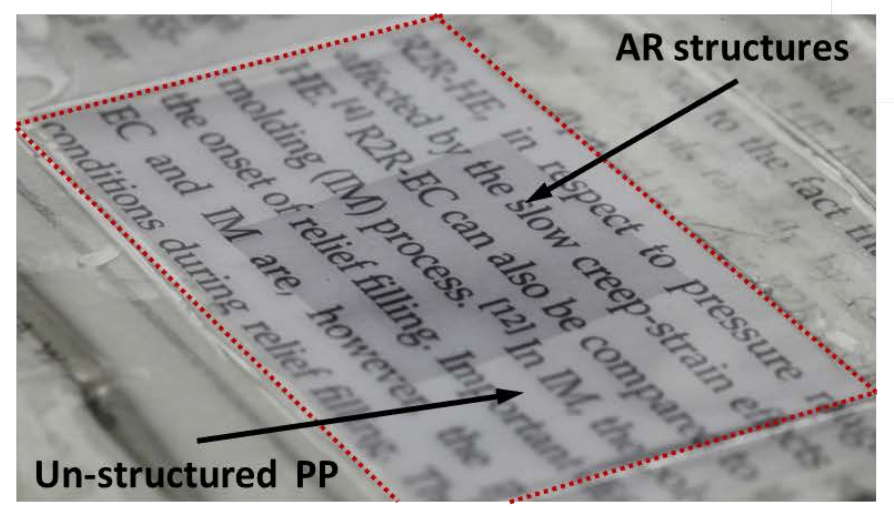

b

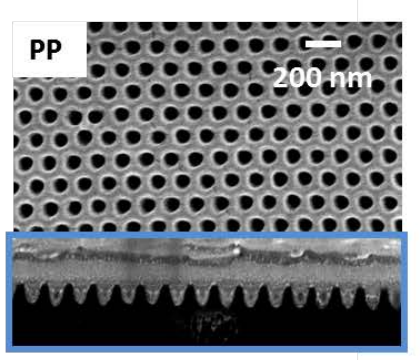

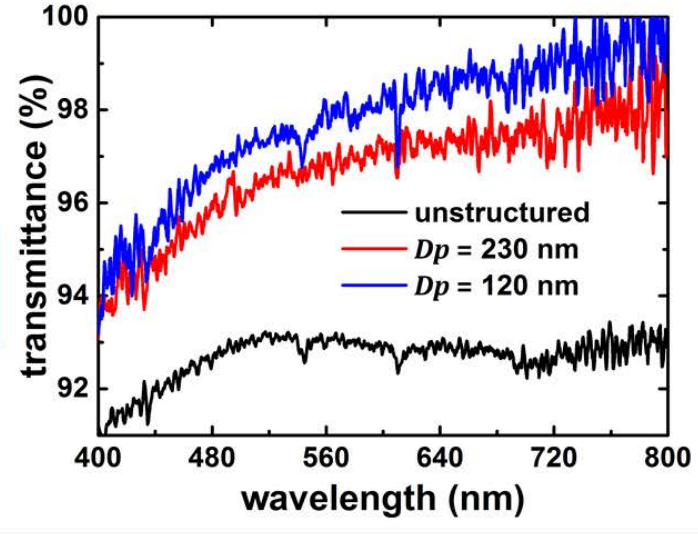

d

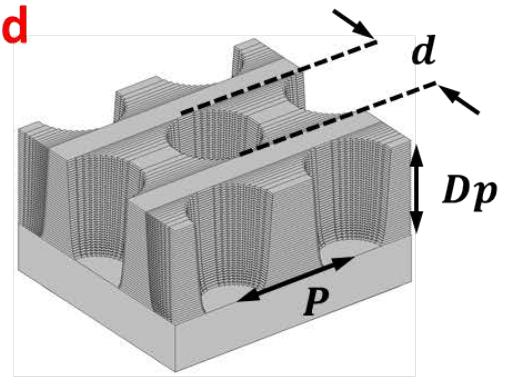

Figure 1. a: SEM image of hexagonal array of nano-pits with $d=100 \mathrm{~nm}$, nominal $P=175 \mathrm{~nm}$ and $D p=240 \mathrm{~nm}$, in Si. Insert at the bottom shows focused ion beam carved scanning electron microscopy (FIB-SEM) cross-section. b: Same structure replicated in PP by R2R-EC. The nanopits in the FIB-SEM images are filled with a protective Pt layer (see methods section), hence why it appears bright. The black part of the images is therefore the substrate ( $\mathrm{Si}$ in $\mathbf{a}$ and polymer in $\mathbf{b}$ ). $\mathbf{c}$ : Measured transmittance versus wavelength of AR foils with nano-pits of $D p=(120 \pm 10) \mathrm{nm}$ and $D p=(230 \pm 10) \mathrm{nm}$, fabricated with a roller line speed of $V_{R}=10 \mathrm{~m} / \mathrm{min}$ and $V_{R}=70 \mathrm{~m} / \mathrm{min}$, respectively, as well as a cooling roller temperature of $T_{C}=40{ }^{\circ} \mathrm{C}$ and $T_{C}=70{ }^{\circ} \mathrm{C}$, respectively. 
The measured transmittance of the unstructured foil is also shown for reference. d: Definition of the geometrical parameters. e: Photograph of a sheet of printed paper laminated with the fabricated foil. The text is seen through the structured AR foil (square patch in the center $-2 \times 2 \mathrm{~cm}^{2}$ ) and the corresponding unstructured foil replicated from an atomically flat Si surface.

The results of this work are summarized in figure 1. The Si master (figure 1a), with $2 \times 2 \mathrm{~cm}^{2}$ area of moth-eye mimicking structures with shapes of tapered nano-pits of depth $D p=240 \mathrm{~nm}$ arranged in a hexagonal array with a pitch length of $P=175 \mathrm{~nm}$, and an opening diameter of $d=100 \mathrm{~nm}$, was fabricated by e-beam lithography and anisotropic dry etching, and then finally replicated in polypropylene (PP) (figure 1b) by the R2R-EC process (figure S1). All structures were replicated from the same Si master, but due to the rheology of the R2R-EC process, they replicated with different $D p$ and different $d$. See figure 1d for the definition of the geometrical parameters. This rheological dependence was controlled by the temperature of the cooling roller $\left(T_{C}\right)$, and the roller line speed $\left(V_{R}\right)$. The AR performance of the foil was recorded over the visible wavelength spectrum by measuring the transmittance through the foil by using the integrating sphere method. The integrating sphere method was employed due to warping of the foil, rendering specular transmittance measurements less reproducible. In figure 1c we show such a measurement for the best performing foil replicated to $D p=(120 \pm 10) \mathrm{nm}$ and for the fully replicated foil with $D p=$ (230 \pm 10$) \mathrm{nm}$, both compared to the corresponding flat foil with no structure. The data in figure 1c were obtained from a single side structured sample, where after, the measured transmittance was converted to the corresponding double side structured transmittance, by exploiting the transmittance data for the unstructured foil (described in methods section). The foils exhibited excellent AR properties at glancing angles as demonstrated in figure 1e, where the foil was laminated onto a sheet of white paper with printed text, and a photograph was made of the text from a glancing angle through the AR foil, using a diffused white light source. The picture clearly illustrates how the text 
becomes clearer when viewed through the structured (square) patch of the foil, whereas the text appears hazy through unstructured foil due to reflection at the top interface.

By keeping the same cooling roller temperature $T_{C}$ at $15{ }^{\circ} \mathrm{C}$ while increasing the roller line-speed $V_{R}$ from $10 \mathrm{~m} / \mathrm{min}$, over $30 \mathrm{~m} / \mathrm{min}$ to $60 \mathrm{~m} / \mathrm{min}$, we observed an increase of replicated $D p$ from (60 $\pm 10) \mathrm{nm}$ for $V_{R}=10 \mathrm{~m} / \mathrm{min}$ to $(100 \pm 10) \mathrm{nm}$ for $V_{R}=60 \mathrm{~m} / \mathrm{min}$. The average transmittance in the visible spectrum increased correspondingly from $(96.0 \pm 1.0) \%$ to $(96.9 \pm 0.8) \%$. When we changed the cooling roller temperature $T_{C}$ to $40{ }^{\circ} \mathrm{C}$, and again varied the speed from $10 \mathrm{~m} / \mathrm{min}$, over $30 \mathrm{~m} / \mathrm{min}$ to $60 \mathrm{~m} / \mathrm{min}$, we observed a further increase of the replicated $D p$ to $(170 \pm 10) \mathrm{nm}$ for $V_{R}=60 \mathrm{~m} / \mathrm{min}$. However, this time the average transmittance achieved a maximum of (98.0 \pm 0.7$)$ $\%$ for the lowest speed of $V_{R}=10 \mathrm{~m} / \mathrm{min}$, but fell to $(97.0 \pm 0.9) \%$ for $V_{R}=60 \mathrm{~m} / \mathrm{min}$. However, this condition, still did not gain full replication of the master structure having a depth $D p \approx 240 \mathrm{~nm}$. Full replication was obtained when $T_{C}$ was cranked up to $70{ }^{\circ} \mathrm{C}$ and $V_{R}$ to $60 \mathrm{~m} / \mathrm{min}$. However, interestingly, full replication with $D p=(230 \pm 10) \mathrm{nm}$ did not result in the highest transmittance, as the measured average transmittance for the full replication condition $\left(T_{C}=70{ }^{\circ} \mathrm{C}\right.$ and $V_{R}=60$ $\mathrm{m} / \mathrm{min})$ only reached $(96.9 \pm 0.6) \%$, and while the condition, $T_{C}=70{ }^{\circ} \mathrm{C}$ and $V_{R}=10 \mathrm{~m} / \mathrm{min}$, resulted in deeper structures than any of the ones produced at $T_{C}=40{ }^{\circ} \mathrm{C}$ and $T_{C}=15{ }^{\circ} \mathrm{C}$, it resulted in the minimum transmittance of $(94.4 \pm 0.3) \%$ apart from the one for the unstructured foil. A comment to make here is that the slightly lower depth of $230 \mathrm{~nm}$ for the PP, as compared to the $240 \mathrm{~nm}$ for the Si master, is attributed to a slight shrinkage of the polymer after cooling. Moreover, the relatively better replication obtained for higher speed is attributed to the semicrystalline nature of PP, whereby the relatively long retardation time for solidification allows the super-cooled PP to reach further inside the nip and get exerted to a higher nip-pressure before solidification, when processed with the higher line-speed. ${ }^{[16]}$ These observations are documented in figure 2. In figure 2a, we plot the average transmittance (averaged over the entire measured 
wavelength range, $400 \mathrm{~nm}-800 \mathrm{~nm}$ ) for the three cooling roller temperature regimes mentioned above as a function of $D p$. To analyze the data, we simulated the transmittance spectra through AR foils with different $D p$, corresponding to the ones in the experiment for various assumed structure shapes shown in the insert of figure 2a, using the rigorous coupled wave analysis (RCWA) method. ${ }^{[22]}$ ) We see, that the data for $T_{C}=15^{\circ} \mathrm{C}$ and $T_{C}=40{ }^{\circ} \mathrm{C}$, seem to be well represented by only altering the depth for a truncated cone (structure A), keeping the top and bottom diameters constant at $110 \mathrm{~nm}$ and $80 \mathrm{~nm}$ respectively. However, the $T_{C}=70{ }^{\circ} \mathrm{C}$ data require more than one geometrical parameter in the simulation. Hence, to simulate the $T_{C}=70{ }^{\circ} \mathrm{C}$ data in figure $2 \mathbf{a}$, we show the simulated depth dependence for structures B and B', where the B' structure differs from the B structure by being more "slim”, i.e. having a narrower top diameter for a given height. In figure $\mathbf{2 b}$, we show the scanning electron images of focused ion-beam carved profiles (FIB-SEM) of the two most relevant structures, namely the one having highest transmittance with $D p=(120 \pm$ 10) $\mathrm{nm}$, and the one with $D p=(200 \pm 10) \mathrm{nm}$ for comparison with simulated profiles. Since all structures were replicated from the same Si master and a mold having an inverted relief (protruding moth-eye pillar structures), we attribute the differences to basically three rheological effects, 1 ) incomplete filling of the voids between pillars in the mold, which seems to be the dominating effect at low cooling roller temperatures, and 2) shrinking of the polymer after replication, which predominantly influences the taper of the nano-pits by making the pits wider, and 3) only to a minor extent, the creep-strain effects encountered in roll-to-roll hot embossing processes ${ }^{[23]}$. The foils fabricated at lower $T_{C}\left(40{ }^{0} \mathrm{C}, 15{ }^{0} \mathrm{C}\right)$ contract more than the foils fabricated at $T_{C}=70{ }^{\circ} \mathrm{C}$, due to the relatively higher polymer cooling rate. Hence the nano-pit diameters for the lower $T_{C}$ foils get enlarged as compared to the Si master, resulting in structures well represented by the truncated cone shaped structures in the simulation (structure A). The simulation further indicates that for the $T_{C}=$ $70{ }^{\circ} \mathrm{C}$ data, the transmittance is sensitive to both the width at the opening of the sigmoidal pits and 
their depth. Hence, in this regime, although we expect less widening of pit diameters (as compared to lower $T_{C}$ ), the deeper structures make the transmittance more sensitive to the width. The PP coating layer fabricated at $10 \mathrm{~m} / \mathrm{min}$ is 6 times thicker than that fabricated at $60 \mathrm{~m} / \mathrm{min}$ (as the polymer feed rate is kept constant), which in turn results in lower polymer cooling rate at $10 \mathrm{~m} / \mathrm{min}$ as compared to $60 \mathrm{~m} / \mathrm{min}$ for a given $T_{C}$ and hence relatively less contraction in the polymer. This can explain why the simulated curve for structure B', fits to the measurement point at $D p=180$ $\mathrm{nm}$, for the sample fabricated at $10 \mathrm{~m} / \mathrm{min}$ and $T_{C}=70{ }^{\circ} \mathrm{C}$, as opposed to the curve for structure $\mathrm{B}$. See figure S2 for SEM images of all polymer structures and figure S3 for the process parameters used.

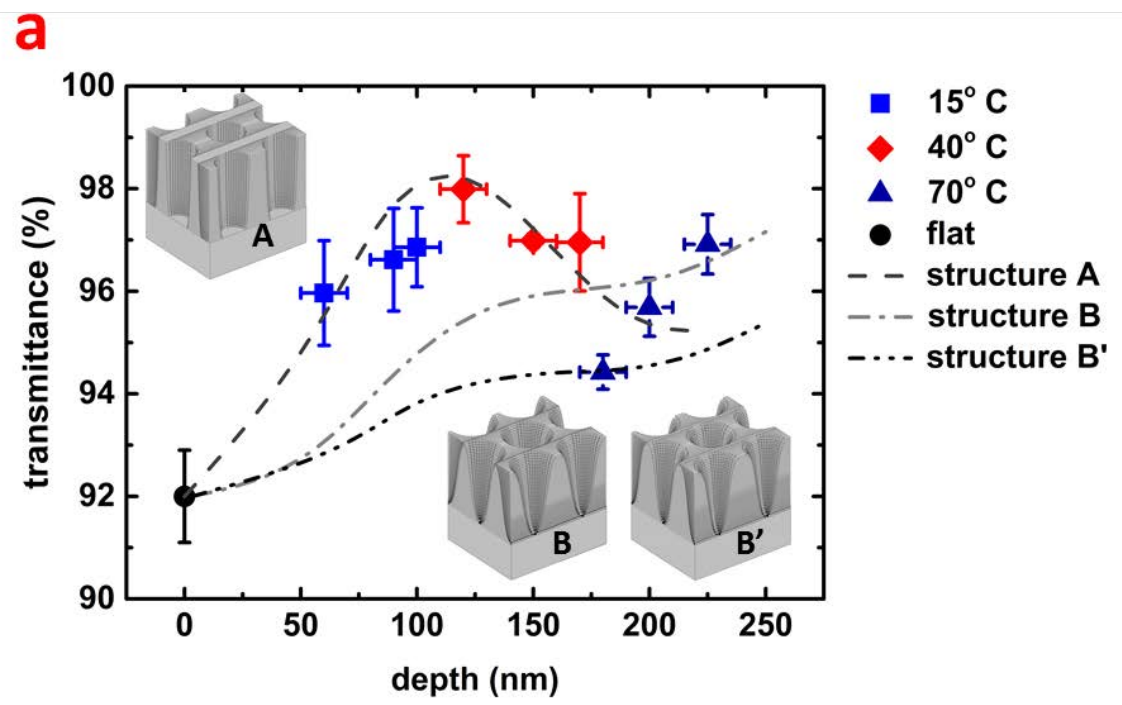

b
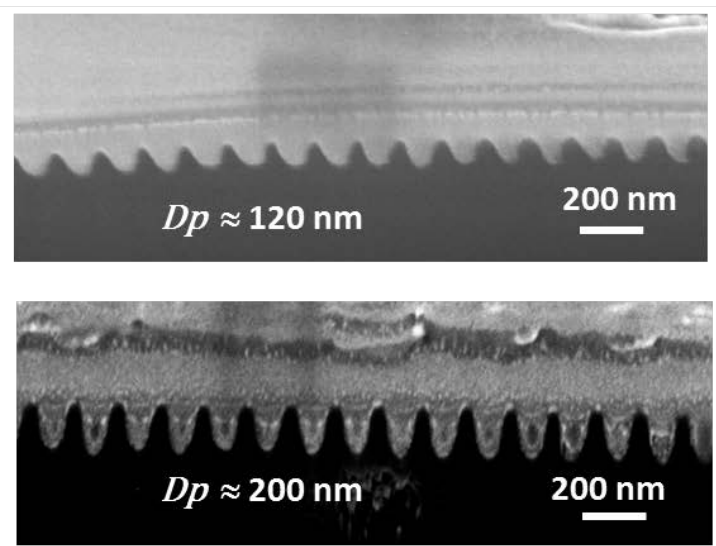
Figure 2. a: Average transmittance of the AR structures between $400-800 \mathrm{~nm}$ fabricated in the three cooling roller temperature regimes $T_{C}=15^{\circ} \mathrm{C}, T_{C}=40^{\circ} \mathrm{C}$, and $T_{C}=70^{\circ} \mathrm{C}$ plotted together with the simulated average transmittance for three model structures A, B, and B'. Inserts show the 3D images of the three model structures at $D p=225 \mathrm{~nm}$, A (truncated conical pit with $P=165$ $\mathrm{nm}$, top diameter $=109 \mathrm{~nm}$, bottom diameter $=80 \mathrm{~nm}$ ), B (sigmoidal pit with $P=165 \mathrm{~nm}$, top diameter $=117 \mathrm{~nm}$ ), and B' (sigmoidal pit $P=165 \mathrm{~nm}$, top diameter $=90 \mathrm{~nm}$ ).b: Standard FIBSEM cross-section of AR foils with $D p=120 \mathrm{~nm}$ and $200 \mathrm{~nm}$.

All the above transmittance measurements, shown in figure $\mathbf{1}$ and figure $\mathbf{2}$, were made on foil samples structured at only one interface (with air) and calculated as if structured on both interfaces; described in the methods section. In order to validate our calculation method and to demonstrate the fabrication of double side structured AR foils by R2R-EC, a single PET carrier foil was structured with nano-pits, at both interfaces by R2R-EC (figure S1), with process parameters $V_{R}=60 \mathrm{~m} / \mathrm{min}$ and $T_{C}=70{ }^{\circ} \mathrm{C}$, resulting in nano-pit depths of $\sim 230 \mathrm{~nm}$ on both sides. Transmittance measurements were made on both single and double side structured samples, fabricated with the same parameters, and compared. This validation is shown in figure 3a, where the broad band transmittance measurement of double side structured foil and single side structured foil match very well, when the single side data are converted to double side data, indicating that there is very little absorption in the bulk of the polymer foil. Further, in order to ascertain the omnidirectional performance of the AR foils, transmittance measurements were made on the double side structured foil, with $D p=(230 \pm 10) \mathrm{nm}$. As seen from figure $3 \mathbf{b}$ the AR foils have similar performance at $30^{\circ}$ incident angle, as at $0^{\circ}$. The minor shifts of the $10^{\circ}$ and $20^{\circ}$ curves are within the experimental uncertainty. In order to investigate the AR performance for angles higher than $30^{\circ}$, an integrating sphere with a larger entrance port $(3 \mathrm{~cm}$ instead of $1 \mathrm{~cm}$ ) had to be used. This, however, had the issue of light emerging from the sphere for the reference measurements, but back-reflected when a 
sample was mounted (see figure S4). This shifted the whole transmittance spectrum to a false higher value. We have measured the amount of back-reflected light by illuminating the integrating sphere from a second port, and then rotate the sample in front of the normal entrance port. From these measurements a correction function of the light intensity as a function of sample rotation has been established. Thereby the large-opening sphere could be used to compare transmittance of normal incidence with the transmittance for higher angles $\left(40^{\circ}\right.$ and $\left.60^{\circ}\right)$. In figure S5, we see that although the overall transmittance level is not trustworthy, we see an overlapping spectral dependence for angles $0^{\circ}, 40^{\circ}$ and $60^{\circ}$ when using this setup. We take all these measurements as an indication of good omnidirectional performance of the AR structures.
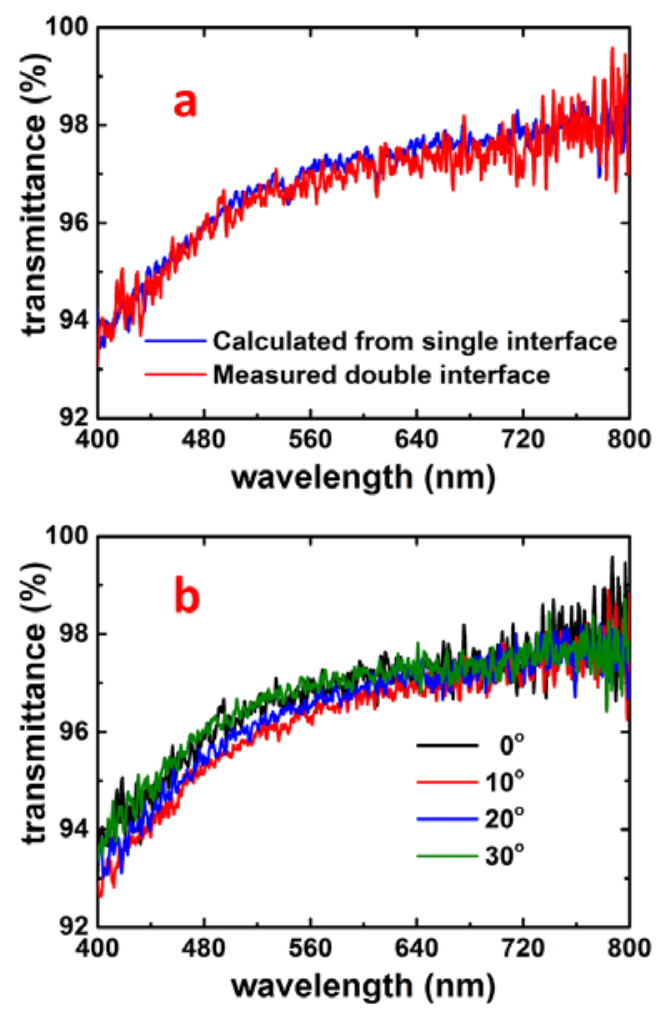

Figure 3 a: Broadband transmittance of the AR foils with nano-pits of $230 \mathrm{~nm}$ depths, structured and calculated from single interface and structured at both interfaces. b: Broadband transmittance, 
at different incident angles $0^{\circ}, 10^{\circ}, 20^{\circ}$, and $30^{\circ}$ of the AR foils with nano-pits of $230 \mathrm{~nm}$ depth and structured on both interfaces.

The AR foils were fabricated by a novel, very high-throughput process known as roll-to-roll extrusion coating, which possesses a number of advantages in terms of productivity and price ${ }^{[16]}$, but could very well also be produced by other roll-to-roll processes, such as roll-to-roll UV assisted nanoimprint lithography ${ }^{[24]}$.

The presented AR foils could potentially be used in consumer products; instead of the multiple layer AR coatings that are used today, with befits of being more cost effective. Further, the presented AR foils have the technological benefits of being fabricated in a single bulk material avoiding multiple film coatings. They have relatively wider acceptance angle and broader spectral range as reflection suppression element, do not require high vacuum processing during manufacturing, and can be applied on curved surfaces and on large areas. In this study pure extrusion grade polymers like PP and PET are used, without any additives, with the potential for integration in medical scope applications. Finally, the nano-pit geometry can potentially be shown to exhibit enhanced scratch resistance properties compared to its nano-pillar counterpart which is more commonly used to make AR surfaces.

The demonstrated AR-foils represent a node-technology with foreseen applications in many technological areas. R2R-EC is a mature technology for the fabrication of smooth polymer films, mainly used in the packaging industry with off-the shelf solutions for R2R addition of e.g. metal and adhesion layers. Single sided AR foils could e.g. be used for foiling of solar panels, and solar concentrators, and through the employment of film-insert molding in light emitting diode housings, in vivo medical imaging, displays, and for low light photography lenses, while double sided AR 
foils could be applied for foiling of greenhouse windows, for food packaging, and for other real life applications especially on transparent surfaces.

\section{Conclusion}

In conclusion, we have demonstrated the fabrication of broadband and omnidirectional antireflective (AR) foils, in the visible spectrum, based on inverted moth eye structures formed as subwavelength tapered nano-pits. By R2R-EC a foil with AR structures on both sides was fabricated at a rate of $60 \mathrm{~m} / \mathrm{min}$, with a web width of $45 \mathrm{~cm}$. The highest, average total transmittance obtained in the visible spectrum was $(98.0 \pm 0.7) \%$, with minimal scattering and absorption losses, and for comparison the unstructured foil has an average transmittance of $(92.0 \pm 0.9) \%$. The broad-band reduction in reflection is documented by transmittance measurements in the visible spectrum (400 $\mathrm{nm}-800 \mathrm{~nm}$ ). To investigate omni-directionality, transmittance measurements were performed for angles up to $60^{\circ}$. The AR foils showed good omnidirectional performance, with no significant difference in transmittance between normal incidence and incidence at $60^{\circ}$. The AR performance of the foil was also investigated for different depths $(D p)$ and shape of the nano-pits. The transmittance initially increased with $D p$ and reached a maximum at $D p \sim 120 \mathrm{~nm}$. For process parameters yielding higher depths, we found that other shape factors along with the depth also played a critical role for the AR properties. 


\section{Author contributions}

SM fabricated the samples. MRL made the computer simulations. SM recorded the SEM and FIBSEM images. NF and MHM made the optical characterizations of the samples. HP, HCP and RT supervised SM. HP and RT conceived the project. SM and RT analyzed the data and wrote the paper.

\section{Acknowledgements}

This work is supported by the Danish National Advanced Technology Foundation (HTF) through the “Advanced Technology Project LANI” (grant 011-2011-3), the “Advanced Technology Platform NanoPlast” (grant 007-2010-2), and by The Danish Ministry of Higher Education and Science, through an industrial PhD scholarship for Swathi Murthy (grant 1355-00143). Mr. Jesper Scheel is acknowledged for taking the photos presented in the paper. Dr. Nis K- Andersen is acknowledged for making the 3d sketch in figure S1. DTU-Danchip is acknowledged for providing and maintaining world class clean-room nanofabrication and nanoscopy facilities. 


\section{References}

[1] P. B. Clapham, M. C. Hutley, Nature 1973, 244, 281; R. Halir, P. J. Bock, P. Cheben, A. OrtegaMonux, C. Alonso-Ramos, J. H. Schmid, J. Lapointe, D. X. Xu, J. G. Wanguemert-Perez, I. MolinaFernandez, S. Janz, Laser \& Photonics Reviews 2015, 9, 25; J. Q. Xi, M. F. Schubert, J. K. Kim, E. F. Schubert, M. F. Chen, S. Y. Lin, W. Liu, J. A. Smart, Nature Photonics 2007, 1, 176; B. Paivanranta, T. Saastamoinen, M. Kuittinen, Nanotechnology 2009, 20.

[2] H. D. Mou, W. H. Hua, Z. N. Yang, Optics Express 2016, 24, 5069; H. K. Raut, V. A. Ganesh, A. S. Nair, S. Ramakrishna, Energy \& Environmental Science 2011, 4, 3779.

[3] K. Choi, S. H. Park, Y. M. Song, Y. T. Lee, C. K. Hwangbo, H. Yang, H. S. Lee, Advanced Materials 2010, 22, 3713.

[4] J. Li, J. Zhu, X. Gao, Small 2014, 10, 2578.

[5] A. R. Parker, H. E. Townley, Nature Nanotechnology 2007, 2, 347.

[6] C. G. Bernhard, W. H. Miller, Acta Physiologica Scandinavica 1962, 56, 385.

[7] R. H. Siddique, G. Gomard, H. Holscher, Nature Communications 2015, 6.

[8] S. Ji, J. Park, H. Lim, Nanoscale 2012, 4, 4603.

[9] L. Schneider, N. A. Feidenhans'l, A. Telecka, R. J. Taboryski, Scientific Reports 2016, 6; A. B. Christiansen, J. Clausen, N. A. Mortensen, A. Kristensen, Applied Physics Letters 2012, 101.

[10] W. H. Southwell, Optics Letters 1983, 8, 584; S. M. Rytov, Soviet Physics Jetp-Ussr 1956, 2, 466.

[11] E. B. Grann, M. G. Moharam, D. A. Pommet, Journal of the Optical Society of America a-Optics Image Science and Vision 1995, 12, 333.

[12] S. A. Boden, D. M. Bagnall, Applied Physics Letters 2008, 93.

[13] K. Hadobas, S. Kirsch, A. Carl, M. Acet, E. F. Wassermann, Nanotechnology 2000, 11, 161.

[14] Y.-F. Huang, S. Chattopadhyay, Y.-J. Jen, C.-Y. Peng, T.-A. Liu, Y.-K. Hsu, C.-L. Pan, H.-C. Lo, C.-H. Hsu, Y.-H. Chang, C.-S. Lee, K.-H. Chen, L.-C. Chen, Nature Nanotechnology 2007, 2, 770.

[15] J. Zhu, Z. Yu, G. F. Burkhard, C.-M. Hsu, S. T. Connor, Y. Xu, Q. Wang, M. McGehee, S. Fan, Y. Cui, Nano Letters 2009, 9, 279.

[16] S. Murthy, M. Matschuk, Q. Huang, N. K. Mandsberg, N. A. Feidenhans'I, P. Johansen, L. Christensen, H. Pranov, G. Kofod, H. C. Pedersen, O. Hassager, R. Taboryski, Advanced Engineering Materials 2016, 18, 484.

[17] S. Murthy, H. Pranov, H. C. Pedersen, R. Taboryski, Journal of Vacuum Science \& Technology B 2016, 34.

[18] A. Telecka, S. Murthy, L. Schneider, H. Pranov, R. Taboryski, Acs Macro Letters 2016, 5, 1034.

[19] M. Burghoorn, D. Roosen-Melsen, J. de Riet, S. Sabik, Z. Vroon, I. Yakimets, P. Buskens, Materials 2013, 6, 3710.

[20] S. Murthy, H. Pranov, H. C. Pedersen, R. Taboryski, Journal of Vacuum Science \& Technology B 2016, 34, 06KM02; A. Telecka, S. Murthy, L. Schneider, H. Pranov, R. Taboryski, ACS Macro Letters 2016, 1034.

[21] N. Gadegaard, S. Thoms, D. S. Macintyre, K. McGhee, J. Gallagher, B. Casey, C. D. W. Wilkinson, Microelectronic Engineering 2003, 67-8, 162; E. Hojlund-Nielsen, T. Greibe, N. A. Mortensen, A. Kristensen, Microelectronic Engineering 2014, 121, 104.

[22] K. Han, C. H. Chang, Nanomaterials 2014, 4, 87; M. G. Moharam, T. K. Gaylord, Journal of the Optical Society of America 1981, 71, 811; Y. C. Chang, G. H. Mei, T. W. Chang, T. J. Wang, D. Z. Lin, C. K. Lee, Nanotechnology 2007, 18.

[23] Y. Deng, P. Yi, L. Peng, X. Lai, Z. Lin, Journal of Micromechanics and Microengineering 2015, 25.

[24] S. H. Ahn, L. J. Guo, Acs Nano 2009, 3, 2304; M. Leitgeb, D. Nees, S. Ruttloff, U. Palfinger, J. Götz, R. Liska, M. R. Belegratis, B. Stadlober, ACS Nano 2016, DOI: 10.1021/acsnano.5b07411. 
